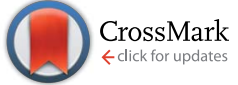

Cite this: J. Mater. Chem. A, 2015, 3, 22794

Received 31st July 2015

Accepted 24th September 2015

DOI: $10.1039 / c 5 t a 05928 c$

www.rsc.org/MaterialsA

\section{A high-performance hydroxyl-functionalized polymer of intrinsic microporosity for an environmentally attractive membrane-based approach to decontamination of sour natural gas $\dagger$}

\begin{abstract}
Shouliang Yi, ${ }^{a}$ Xiaohua Ma, ${ }^{b}$ Ingo Pinnau*b and William J. Koros ${ }^{\star a}$
Acid gases carbon dioxide $\left(\mathrm{CO}_{2}\right)$ and hydrogen sulfide $\left(\mathrm{H}_{2} \mathrm{~S}\right)$ are important and highly undesirable contaminants in natural gas, and membrane-based removal of these contaminants is environmentally attractive. Although removal of $\mathrm{CO}_{2}$ from natural gas using membranes is well established in industry, there is limited research on $\mathrm{H}_{2} \mathrm{~S}$ removal, mainly due to its toxic nature. In actual field operations, wellhead pressures can exceed 50 bar with $\mathrm{H}_{2} \mathrm{~S}$ concentrations up to $20 \%$. Membrane plasticization and competitive mixed-gas sorption, which can both lead to a loss of separation efficiency, are likely to occur under these aggressive feed conditions, and this is almost always accompanied by a significant decrease in membrane selectivity. In this paper, permeation and separation properties of a hydroxylfunctionalized polymer with intrinsic microporosity (PIM-6FDA-OH) are reported for mixed-gas feeds containing $\mathrm{CO}_{2}, \mathrm{H}_{2} \mathrm{~S}$ or the combined pair with $\mathrm{CH}_{4}$. The pure-gas permeation results show no $\mathrm{H}_{2} \mathrm{~S}$ induced plasticization of the PIM-6FDA-OH film in a pure $\mathrm{H}_{2} \mathrm{~S}$ feed at $35^{\circ} \mathrm{C}$ up to 4.5 bar, and revealed only a slight plasticization up to 8 bar of pure $\mathrm{H}_{2} \mathrm{~S}$. The hydroxyl-functionalized PIM membrane exhibited a significant pure-gas $\mathrm{CO}_{2}$ plasticization resistance up to 28 bar feed pressure. Mixed-gas $\left(15 \% \quad \mathrm{H}_{2} \mathrm{~S} / 15 \% \quad \mathrm{CO}_{2} / 70 \% \quad \mathrm{CH}_{4}\right)$ permeation results showed that the hydroxyl-functionalized PIM membrane maintained excellent separation performance even under exceedingly challenging feed conditions. The $\mathrm{CO}_{2}$ and $\mathrm{H}_{2} \mathrm{~S}$ permeability isotherms indicated minimal $\mathrm{CO}_{2}$-induced plasticization; however, $\mathrm{H}_{2} \mathrm{~S}$-induced plasticization effects were evident at the highest mixed gas feed pressure of 48 bar. Under this extremely aggressive mixed gas feed, the binary $\mathrm{CO}_{2} / \mathrm{CH}_{4}$ and $\mathrm{H}_{2} \mathrm{~S} / \mathrm{CH}_{4}$ permselectivities, and the combined $\mathrm{CO}_{2}$ and $\mathrm{H}_{2} \mathrm{~S}$ acid gas selectivity were 25, 30 and 55, respectively. Our results indicate that $\mathrm{OH}$-functionalized PIM materials are very promising candidate membrane materials for simultaneous removal of $\mathrm{CO}_{2}$ and $\mathrm{H}_{2} \mathrm{~S}$ from aggressive natural gas feeds, which makes membrane-based gas separation technology an attractive option for clean energy production and reducing greenhouse gas emissions.
\end{abstract}

\section{Introduction}

With the continuing growth in global population and development, the total worldwide demand for energy is projected to rapidly expand in the near future. In the Annual Energy Outlook (AEO) 2014 Reference case, total delivered energy consumption in the industrial sector is projected to increase by $28 \%$ from 2012 to $2040 .{ }^{1}$ Much of the growth will reflect natural gas use, which is projected to account for $34 \%$ of the total

${ }^{a}$ School of Chemical and Biomolecular Engineering, Georgia Institute of Technology, 311Ferst Drive, Atlanta, GA 30332, USA. E-mail: bill.koros@chbe.gatech.edu

${ }^{b}$ Advanced Membranes and Porous Materials Center, Physical Sciences and Engineering Division, King Abdullah University of Science and Technology, Thuwal 23955-6900, Saudi Arabia. E-mail: ingo.pinnau@kaust.edu.sa

$\dagger$ Electronic supplementary information (ESI) available: Pure and mixed gas permeation modelling. See DOI: 10.1039/c5ta05928c increase in energy consumption from 2012 to 2025 and 59\% of the increase from 2025 to 2040 . One of the reasons for this trend is that natural gas has relatively low carbon footprint, increased thermal efficiency, and cleaner burning benefits compared to other fossil fuels. These advantages make natural gas one of the cleanest and most efficient energy sources. Despite this promising outlook, raw natural gas can contain significant amounts of impurities such as hydrogen sulfide $\left(\mathrm{H}_{2} \mathrm{~S}\right)$, carbon dioxide $\left(\mathrm{CO}_{2}\right)$, water vapor, higher hydrocarbons, nitrogen, and other inert gases, which must be removed before pipeline delivery to industrial or household users. Among these impurities, the acid gas components $\mathrm{CO}_{2}$ and $\mathrm{H}_{2} \mathrm{~S}$ are particularly important to be removed. Typical pipeline specifications in the US mandate a $\mathrm{H}_{2} \mathrm{~S}$ concentration below $4 \mathrm{ppm}$ and $\mathrm{CO}_{2}$ concentration below $2 \%{ }^{2}$ Over $30 \%$ of the gas produced in the United States and over $40 \%$ of proven raw natural gas reserves 
contain $\mathrm{CO}_{2}$ and $\mathrm{H}_{2} \mathrm{~S}$ above acceptable levels, and these wells are classified as sour gas. ${ }^{3}$ Recently, $\mathrm{H}_{2} \mathrm{~S}$ removal has received more attention, because in certain areas in the US, Canada, Russia, and the Middle East, oil and gas reservoirs were reported to contain $\mathrm{H}_{2} \mathrm{~S}$ as well as $\mathrm{CO}_{2}$ at varying high levels. ${ }^{4-6}$ Currently, amine absorption dominates acid gas $\left(\mathrm{CO}_{2}\right.$ and $\left.\mathrm{H}_{2} \mathrm{~S}\right)$ separation technology to reduce $\mathrm{CO}_{2}$ and $\mathrm{H}_{2} \mathrm{~S}$ to meet the pipeline requirement $\left(<2 \% \mathrm{CO}_{2},<4 \mathrm{ppm} \mathrm{H}_{2} \mathrm{~S}\right)$. Such processes present environmental concerns as well as high capital and maintenance costs of the large absorption units. ${ }^{7}$ On the other hand, compared to conventional absorption processes, membrane-based gas separation offers a potentially more energy efficient technology with low capital cost, small footprint, simple operation, and low maintenance, as well as minimal environmental impact. ${ }^{2,7}$ Membrane technology may also provide options for the bulk removal of $\mathrm{CO}_{2}$ and $\mathrm{H}_{2} \mathrm{~S}$, as well as other impurities through hybrid absorption-membrane processes. $^{7}$ Despite these advantages, membrane-based processes require the development of improved membrane materials with both high productivity and high selectivity to minimize capital and operating cost. ${ }^{2,8-10}$ Moreover, for systems of highly interacting species such as $\mathrm{CO}_{2}$ and $\mathrm{H}_{2} \mathrm{~S}$, the stability of a membrane material to resist penetrant-induced plasticization presents an additional challenge.

Commercially available polymers for gas separation membranes (polysulfone, cellulose acetate, polyimide, etc.) are limited by their moderate permeability and selectivity., 11-13 The most promising materials, glassy polyimides, especially 6FDA-based polyimides offer: (i) solubility in common processing solvents, (ii) thermal and chemical stability, and (iii) robust mechanical properties under highpressure natural gas feeds. ${ }^{\mathbf{1 0}}$ Moreover, some polyimides also offer excellent intrinsic $\mathrm{CO}_{2} / \mathrm{CH}_{4}$ separation properties, i.e., high productivity and selectivity for feeds with low $\mathrm{CO}_{2}$ partial pressures, and are processable into thin-skinned hollow-fibers by standard commercial fabrication processes. ${ }^{3,8,10,14-29}$ While many membrane materials have been developed for the separation of $\mathrm{CO}_{2} / \mathrm{CH}_{4}$ over the past several decades, only a few studies have focused on the development of materials for removal of all natural sour gas components due to the high toxicity of $\mathrm{H}_{2} \mathrm{~S} .^{3,4,11,21,22,24}$ To safely handle $\mathrm{H}_{2} \mathrm{~S}$, additional strict safety measures are required, so the few literature studies addressing $\mathrm{H}_{2} \mathrm{~S}$ removal using membranes have generally focused on relatively low $\mathrm{H}_{2} \mathrm{~S}$ concentration and feed pressure. ${ }^{11,30}$ Such studies show that polymers with high $\mathrm{H}_{2} \mathrm{~S}$ / $\mathrm{CH}_{4}$ selectivities usually show $\mathrm{CO}_{2} / \mathrm{CH}_{4}$ selectivities of less than 10-15. ${ }^{11}$ Chatterjee et al. investigated the sour gas permeation properties for several rubbery polymers with selectivities as high as 74 for $\mathrm{H}_{2} \mathrm{~S} / \mathrm{CH}_{4}\left(1.3 \% \mathrm{H}_{2} \mathrm{~S}\right.$ feed) for a feed pressure of 14 bar with $\mathrm{H}_{2} \mathrm{~S}$ molar concentrations of $1.3 \%$ and $12.5 \%$. Mohammadi et al. studied the acid gas permeation behavior of poly(ester urethane urea) membranes. Although $\mathrm{H}_{2} \mathrm{~S} / \mathrm{CH}_{4}$ selectivities of 34 and 43 were achieved for $0.6 \% \mathrm{H}_{2} \mathrm{~S}$ and $3 \% \mathrm{H}_{2} \mathrm{~S}$ feed, respectively, the corresponding moderate $\mathrm{CO}_{2} / \mathrm{CH}_{4}$ selectivity was only 14 . Furthermore, their studies were performed for feed pressures less than 30 bar. $^{30}$ These conditions are unlikely to reflect the most aggressive operating conditions in natural gas applications. Because many gas well pressures can reach 50 bar or higher, more aggressive feeds need to be considered, and this is the focus of our work. Feed streams containing both $\mathrm{CO}_{2}$ and $\mathrm{H}_{2} \mathrm{~S}$ with relatively high total acid gas concentration and partial pressures require more robust materials capable of removing both acid gases, with stable properties. ${ }^{\mathbf{2 4}}$

Recently, a number of advanced polymers, including 6FDADAM : DABA (3:2), and 6FDA-based poly-amide-imides, have been developed for aggressive sour gas separations., ${ }^{3,21,22}$ The goal of the present work was to develop another novel membrane material for the simultaneous removal of $\mathrm{H}_{2} \mathrm{~S}$ and $\mathrm{CO}_{2}$ from natural gas under aggressive feed conditions. To the best of our knowledge, intrinsically microporous polyimides have never been applied for sour gas separations. In this paper, we report, for the first time, a novel thermally annealed hydroxyl-functionalized polyimide with intrinsic microporosity (PIM-6FDA-OH) for simultaneous removal of $\mathrm{CO}_{2}$ and $\mathrm{H}_{2} \mathrm{~S}$ from natural gas under aggressive feed conditions. Specifically, the performance of PIM-6FDA-OH was tested with high concentrations of $\mathrm{H}_{2} \mathrm{~S}$ and $\mathrm{CO}_{2}$ feeds as well as high feed pressures.

\section{Background and theory}

\section{Gas permeation}

The transport of gases through dense polymeric membranes involves the sorption-diffusion mechanism in which the penetrant first sorbs into the membrane at the upstream feed side, then diffuses across the membrane down a concentration gradient, and finally desorbs from the downstream permeate side. Gas permeation in such cases is characterized by the permeability coefficient, $P$. As shown in eqn (1), the permeability of a gas $i\left(P_{i}\right)$ is defined as the steady-state flux $n_{i}$ normalized by the driving partial pressure $\left(\Delta p_{i}\right)$ across the membrane and the membrane thickness $(l)$.

$$
P_{i}=\frac{n_{i} l}{\Delta p_{i}}
$$

Permeability is commonly expressed in units of Barrer, where 1 Barrer $=1 \times 10^{-10}\left(\mathrm{~cm}^{3} \mathrm{STP} \mathrm{cm} \mathrm{cm}^{-2} \mathrm{~s}^{-1} \mathrm{cmHg}^{-1}\right)$.

In the case of nonideal gas mixtures, an alternative definition of permeability is used to describe the permeation driving force in terms of a fugacity difference rather than a partial pressure difference. For dense films, the fugacity-based permeability, which is used throughout this study, is defined as the flux $\left(n_{i}\right)$, normalized by the transmembrane fugacity driving force of component $i\left(\Delta f_{i}\right)$ and membrane thickness $(l)$, as shown in eqn (2).

$$
P_{i}=\frac{n_{i} l}{\Delta f_{i}}
$$

The fugacity coefficients of pure $\mathrm{H}_{2} \mathrm{~S}, \mathrm{CO}_{2}$ and $\mathrm{CH}_{4}$ as well as their state in gas mixtures can be calculated using the PengRobinson equation-of-state and the SUPERTRAPP program developed by NIST. ${ }^{22}$ 
Permeability can also be expressed as the product of the effective diffusion coefficient, $D$, and sorption coefficient, $S$, of a given gas $i$ within the membrane, as described in eqn (3).

$$
P_{i}=D_{i} S_{i}
$$

The diffusion coefficient characterizes the kinetic contribution to transport, and the apparent diffusion coefficient $D\left(\mathrm{~cm}^{2}\right.$ $\mathrm{s}^{-1}$ ) of the polymer membrane can be calculated by $D=l^{2} / 6 \theta$, where $l$ is the membrane thickness and $\theta$ is the time lag as deduced from pure-gas permeability measurements. The sorption coefficient $S\left(\mathrm{~cm}^{3}\right.$ (STP) $\left.\mathrm{cm}^{-3} \mathrm{cmHg}^{-1}\right)$ can then be obtained from the relationship $S=P / D$.

The sorption coefficient represents the thermodynamic contribution to transport, and it can also be measured independently by pressure-decay sorption to allow $D$ to be calculated from $D=P / S$. As shown in eqn (4), for cases with negligible downstream pressure, the sorption coefficient can be expressed as:

$$
S_{i}=\frac{c_{i}}{f_{i}}
$$

where $c_{i}$ is the concentration of a gas sorbed in the membrane, and $f_{i}$ is the corresponding upstream fugacity driving force of component $i$. For glassy polymers, this relationship is often described by the dual-mode sorption model, which is given as: $^{31,32}$

$$
c_{i}=c_{\mathrm{D}, i}+c_{\mathrm{H}, i}=k_{\mathrm{D}, i} f_{i}+\frac{C_{\mathrm{H}, i}^{\prime} b_{i} f_{i}}{1+b_{i} f_{i}}
$$

where $c_{\mathrm{D}, i}$ is the Henry's law or dissolved mode penetrant concentration, $c_{\mathrm{H}, i}$ is the penetrant concentration in the Langmuir mode or hole-filling sorption mode. In eqn $(5), k_{\mathrm{D}, i}$ is the Henry's law sorption coefficient, $C^{\prime}{ }_{\mathrm{H}, i}$ is the Langmuir capacity constant, and $b_{i}$ is the Langmuir affinity constant. As with permeability, fugacity $\left(f_{i}\right)$ values are substituted in place of pressure values to connect more directly to the true thermodynamic properties of the penetrants.

Koros et al. extended the dual-mode sorption model represented by eqn (5) to account for competition in binary gas mixtures at concentrations below which swelling induced complications occur. ${ }^{33,34}$ Recently, this dual-mode model was used for ternary mixed gas feed cases by Kraftschik et al. ${ }^{24}$ The ternary mixed gas dual-mode sorption model for components $A$, $B$ and $C$ can be given in eqn (6)-(8).

$$
\begin{aligned}
& c_{A}=k_{\mathrm{D}, A} f_{A}+\frac{C_{\mathrm{H}, A}^{\prime} b_{A} f_{A}}{1+b_{A} f_{A}+b_{B} f_{B}+b_{C} f_{C}} \\
& c_{B}=k_{\mathrm{D}, B} f_{B}+\frac{C_{\mathrm{H}, B}^{\prime} b_{B} f_{B}}{1+b_{A} f_{A}+b_{B} f_{B}+b_{C} f_{C}} \\
& c_{C}=k_{\mathrm{D}, C} f_{C}+\frac{C_{\mathrm{H}, C}^{\prime} b_{C} f_{C}}{1+b_{A} f_{A}+b_{B} f_{B}+b_{C} f_{C}}
\end{aligned}
$$

The ideal selectivity between the fast gas $(i)$ and slow gas $(j)$, defined as the ratio of permeabilities (eqn (9)), equals the mixed-gas "separation factor" (eqn (10)) when the downstream pressure is negligible compared to the feed pressure, as valid in the current study.

$$
\alpha_{i / j}=\frac{P_{i}}{P_{j}}=\frac{D_{i}}{D_{j}} \frac{S_{i}}{S_{j}}=\alpha_{\mathrm{D}} \alpha_{\mathrm{S}}
$$

where $\alpha_{\mathbf{D}}$ is the diffusivity or mobility selectivity and $\alpha_{\mathrm{S}}$ is the sorption selectivity. Moreover, for actual mixed gas feeds,

$$
\alpha_{i / j}=\frac{\left(y_{i} / y_{j}\right)}{\left(x_{i} / x_{j}\right)}
$$

where $y_{i}$ is the mole fraction of component $(i)$ on the permeate side, and $x_{i}$ is the mole fraction of component $(i)$ on the feed side of the membrane, as measured by gas chromatography (GC).

\section{Experimental}

\section{Materials}

As noted earlier, ${ }^{35}$ the monomer $4,4^{\prime}$-(hexafluoroisopropylidene) diphthalic anhydride (6FDA, 99\%) was obtained from Aldrich and purified by sublimation before use. $\mathrm{N}$-Methylpyrrolidone (NMP) was refluxed over $\mathrm{P}_{2} \mathrm{O}_{5}$ for $4 \mathrm{~h}$ before vacuum distillation and, thereafter, stored over $4 \AA$ molecular sieves. Pyridine was distilled freshly prior to use. Bisphenol A, methylsulfonic acid, dichlorotin hydrochloride acid solution, sodium carbonate, tetrahydrofuran, dichloromethane, ethyl acetate, ligroin, acetic acid, and nitric acid were obtained from Aldrich and used as received. $\mathrm{CO}_{2}$ and $\mathrm{CH}_{4}$ with $99.999 \%$ purity were obtained from Airgas, whereas $\mathrm{H}_{2} \mathrm{~S}$ was obtained from Praxair with 99.6\% purity. The ternary gas mixture used was also obtained from Praxair with a composition of $15 \mathrm{vol} \% \mathrm{H}_{2} \mathrm{~S}, 15 \mathrm{vol} \% \mathrm{CO}_{2}$, and 70 vol\% $\mathrm{CH}_{4}$.

\section{Synthesis of PIM-6FDA-OH}

The pristine polymer PIM-6FDA-OH was synthesized according to the previously reported method. ${ }^{35}$ Briefly, the diamine monomer, 3,3,3',3'-tetramethyl-1,1' $1^{\prime}$-spirobisindane-5, $5^{\prime}$-diamino-6, $6^{\prime}$-diol, with $o$-OH groups was first synthesized. 4, $4^{\prime}$ (Hexafluoroisopropylidene) diphthalic anhydride (6FDA) was then reacted with the diamine monomer for polymerization via a solvothermal azeotropic imidization reaction. In this way, the hydroxyl-functionalized PIM-structured polyimide (PIM-PI) was obtained, which is denoted here as PIM-6FDA-OH. The chemical structure of PIM-6FDA-OH is shown in Fig. 1. This rigid polymer does not show a true glass transition temperature, and it degrades at high temperature $\left(>380{ }^{\circ} \mathrm{C}\right)$. Note that the presence of the polar $\mathrm{OH}$ group in PIM-6FDA-OH provides added cohesive forces to stabilize the matrix against acid gas plasticization.

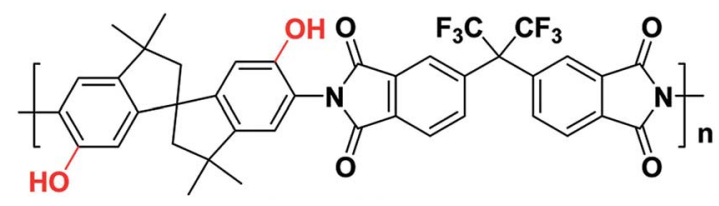

Fig. 1 Chemical structure of the PIM-6FDA-OH polymer. 
Fortunately, it is the standard procedure to remove moisture from natural gas feeds to produce noncorrosive dry gases with low "dew points". This fact eliminates possible concern regarding the hydrophilicity of the PIM-6FDA-OH. ${ }^{36}$

\section{Membrane fabrication}

The polymer (PIM-6FDA-OH) was dissolved in THF to form a 3-5 $\mathrm{wt} \%$ polymer solution and placed on a roller for at least $24 \mathrm{~h}$ for mixing, then purified using $1.0 \mu \mathrm{m}$ PTFE filter cartridges. The polymer solution was used to prepare polymer dense films by a solution casting method in a glove bag at room temperature to achieve slow evaporation (3-4 days) and the vitrified films were then removed and dried in a vacuum oven at $120^{\circ} \mathrm{C}$ for at least $12 \mathrm{~h}$ to remove residual solvent. Finally, the films were thermally annealed at $250{ }^{\circ} \mathrm{C}$ for $24 \mathrm{~h}$ under high vacuum. This annealing step has been shown earlier in studies with $\mathrm{CO}_{2}$ and $\mathrm{CH}_{4}$ to stabilize the polymer matrix against plasticization. ${ }^{37}$ The thicknesses and effective areas of the films were measured using a digital micrometer and image processing software, respectively.

\section{Permeation measurements}

Pure and mixed gas permeation experiments were performed using $\mathrm{H}_{2} \mathrm{~S}, \mathrm{CO}_{2}$, and $\mathrm{CH}_{4}$ as well as a ternary mixture of these three components. While there are few studies reported on $\mathrm{H}_{2} \mathrm{~S}$ containing feeds, for the aggressive feeds considered here, a special facility was needed. The detailed description of this facility is provided in reference, which is available electronically on the link http://hdl.handle.net/1853/50289. ${ }^{38}$ Nevertheless, a short summary of the key procedures followed is provided. Dense film permeation was conducted at $35{ }^{\circ} \mathrm{C}$ using a previously described constant volume/variable pressure permeation apparatus. ${ }^{39-41}$ The membranes were degassed in the permeation system on both sides under high vacuum at $35{ }^{\circ} \mathrm{C}$ for at least $24 \mathrm{~h}$ before any permeation test. Several modifications were made to the standard permeation system design to ensure safety when handling $\mathrm{H}_{2} \mathrm{~S}$ and high concentration $\mathrm{H}_{2} \mathrm{~S}$ gas mixtures. ${ }^{4,22}$ The permeation cell was additionally enclosed in a large ventilated cabinet as a secondary compartment to prevent $\mathrm{H}_{2} \mathrm{~S}$ exposure if a leak was to occur in the system. In addition, two pneumatically actuated valves were used in place of standard hand-operated valves and controlled by a Labview ${ }^{\circledR}$ program for additional safety. In addition, the downstreamactuated valve was programmed to shut down when the downstream pressure reached a certain maximum pressure to avoid over-pressurization that may damage the pressure transducers, and also to prevent unintended release of large quantities of $\mathrm{H}_{2} \mathrm{~S}$ and minimize operator risk when handling $\mathrm{H}_{2} \mathrm{~S}$.

To measure permeability, the gas was first introduced on the feed side and allowed to fill a ballast volume. The pneumatically actuated valve was then opened on the Labview® program to feed the membrane on the upstream side. As the gas permeated through the membrane to the downstream (permeate) side, the increase in pressure with time was recorded using the Labview ${ }^{\circledR}$ program until steady-state was reached. To ensure attainment of true steady state, the total flux was monitored until a constant value was achieved and then compositional steady state was verified. Specifically, not only was it verified that the total flux was constant, but also that the mole fraction composition of the various components contributing to the total flux was constant. As a practical matter, the attainment of total flux steady state and permeate compositional steady state coincided. This fact notwithstanding the achievement of steady state exceeded the expected time based on sample Fickian transport. Nevertheless, once steady state was achieved, it was stable. The upstream pressure was maintained constant throughout the experiment and also recorded using Labview ${ }^{\circledR}$. A downstream pressure $v$ s. time plot was then generated using the collected data. A Varian 450-GC was used during mixed gas permeation experiments to determine the permeate gas composition. The feed pressure and retentate flow were maintained by keeping the stage cut below 1\% using an ISCO syringe pump and a metering valve. The syringe pump was maintained at constant pressure and the gas was fed at the same rate as the retentate vented through the metering valve. A low stage cut was used to: (i) prevent concentration polarization on the upstream side and (ii) maintain essentially a constant feed and residue concentration in order to provide a constant driving force across the membrane during the experiment. A high-temperature epoxy, Duralco $^{\mathrm{TM}} 4525$ (Cotronics Corp.), was used on all samples to seal the membrane-tape masking interface. This was done to prevent delamination of the masked films, which has been observed with less durable sealing epoxies when using highly sorbing species such as $\mathrm{CO}_{2}$ and, in particular, $\mathrm{H}_{2} \mathrm{~S}^{22}$

\section{Pure gas sorption}

Pure gas sorption experiments were performed with $\mathrm{H}_{2} \mathrm{~S}, \mathrm{CO}_{2}$, and $\mathrm{CH}_{4}$. A pressure decay sorption apparatus was used to measure the sorption isotherms of the PIM-6FDA-OH dense film at $35{ }^{\circ} \mathrm{C}^{\mathbf{4 2}}$ These systems have been described in detail elsewhere, but a few minor alterations were made to ensure operator safety when experimenting with $\mathrm{H}_{2} \mathrm{~S}$., ${ }^{\mathbf{4} 22}$ The density of the polymer was determined gravimetrically by its measured weight, area, and film thickness. ${ }^{35}$ The density measurement was used to calculate the fractional free volume of the polymer and the sorption capacities.

\section{Results and discussion}

\section{Pure gas permeation}

Pure gas permeation experiments were performed on the thermally annealed PIM-6FDA-OH films using $\mathrm{H}_{2} \mathrm{~S}, \mathrm{CO}_{2}$, and $\mathrm{CH}_{4}$ at $35{ }^{\circ} \mathrm{C}$ with the constant-volume/variable-pressure apparatus, previously mentioned for handling $\mathrm{H}_{2} \mathrm{~S}$ gas mixtures. ${ }^{4}$ Both low and high pressures were studied to compare the transport properties of these annealed films with values reported in the previous literature. ${ }^{35}$ All permeability calculations used the fugacity driving force definition of dense film permeability that has been reported for highly aggressive feed streams, such as those with elevated $\mathrm{CO}_{2}$ or $\mathrm{H}_{2} \mathrm{~S}$ levels. ${ }^{22}$ The permeability was calculated from the steady-state region of the downstream pressure-time curve, and the diffusion coefficient $(D)$ was 
determined by the time-lag method. The pure gas results of the thermally annealed PIM-6FDA-OH films and other polymer materials were plotted on permeability-selectivity trade-off curves ${ }^{12,13}$ for $\mathrm{CO}_{2} / \mathrm{CH}_{4}$ in Fig. 2 and $\mathrm{H}_{2} \mathrm{~S} / \mathrm{CH}_{4}$ in Fig. 3. It can be seen from Fig. 2 that the PIM-6FDA-OH membranes are more permeable than conventional $\mathrm{OH}$-functionalized polyimides owing to the microporosity introduced by the spiro-induced contorted structure of the polymer. For example, the $\mathrm{CO}_{2}$ permeability coefficient of the thermally annealed PIM-6FDA$\mathrm{OH}$ film in this work is 149 Barrers, whereas conventional $\mathrm{OH}$ containing polyimides typically have $\mathrm{CO}_{2}$ permeabilities of less than 20 barrers. $^{43}$ As shown in Fig. 2, the thermally annealed PIM-6FDA-OH films have much higher $\mathrm{CO}_{2} / \mathrm{CH}_{4}$ selectivity than traditional PIM-1 and PIM-PIs. Because $\mathrm{a}_{2} \mathrm{~S} / \mathrm{CH}_{4}$ upper bound plot does not exist yet in the literature due to the limited amount of data available for this gas pair, we only show our current polymer performance relative to other reported data. As shown in Fig. 3, the thermally annealed PIM-6FDA-OH film has a reasonable $\mathrm{H}_{2} \mathrm{~S} / \mathrm{CH}_{4}$ selectivity and shows much higher $\mathrm{H}_{2} \mathrm{~S}$ permeability than other glassy polymers such as $\mathrm{CA}, 6 \mathrm{~F}-\mathrm{PAI}$, and 6FDA-DAM-DABA ( $3: 2)$, similar to the PEG crosslinked 6FDADAM-DABA (PEGMC) material reported earlier, ${ }^{24}$ indicating that the PIM-6FDA-OH material is very promising for sour gas separations.

\section{Pure gas sorption}

Sorption measurements for the sour gas components were performed on thermally annealed PIM-6FDA-OH films using the pressure decay method ${ }^{42,46}$ at $35{ }^{\circ} \mathrm{C}$. The films were dried in a vacuum oven at $100{ }^{\circ} \mathrm{C}$ for at least $12 \mathrm{~h}$ prior to testing to remove any moisture. The sample cell was then evacuated for 2 days prior to testing and evacuated for $24 \mathrm{~h}$ at the completion of each gas isotherm. The results of $\mathrm{H}_{2} \mathrm{~S}, \mathrm{CO}_{2}$ and $\mathrm{CH}_{4}$ pure gas sorption experiments are shown in Fig. 4. The "dual-mode" sorption model with both Langmuir (hole-filling) and Henry's law (dissolution) is apparent in the concave sorption isotherms. The

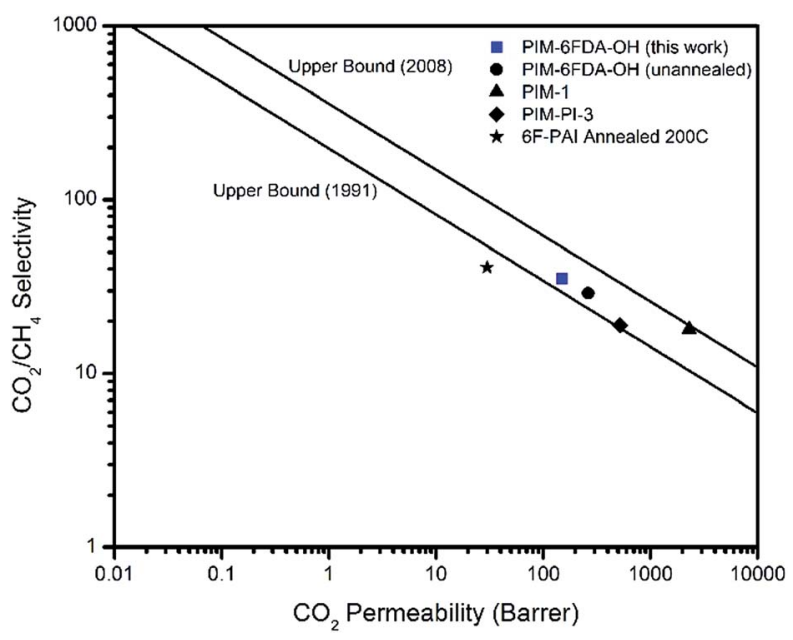

Fig. $2 \mathrm{CO}_{2} / \mathrm{CH}_{4}$ permeability-selectivity trade-off curve $\mathrm{e}^{12,13}$ comparison of thermally annealed PIM-6FDA-OH to other polymers materials $3,35,44,45$ in pure-gas feeds at $35^{\circ} \mathrm{C}$.

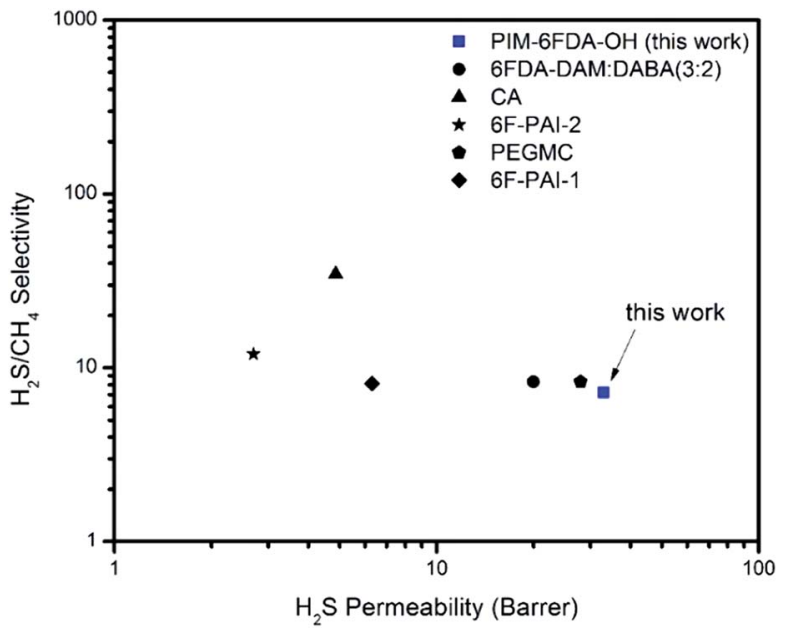

Fig. $3 \mathrm{H}_{2} \mathrm{~S} / \mathrm{CH}_{4}$ permeability-selectivity trade-off comparison of thermally annealed PIM-6FDA-OH to other polymers materials 3,4,22,24 in pure-gas feeds at 4.5 bar and $35^{\circ} \mathrm{C}$.

dual-mode sorption model was then fitted using the leastsquares method to the dual-mode sorption equation to each of the sorption isotherms to give dual-mode sorption parameters. Good agreement between the model and the sorption data was achieved over the pressure range tested. It should be noted here at higher pressures, $\mathrm{H}_{2} \mathrm{~S}$ swelling in GCV-modified CA and 6FDA-DAM-DABA $(3: 2)$ was apparent and marked by a deviation from the dual-mode fit, which was not observed for the thermally annealed PIM-6FDA-OH films. ${ }^{22,24}$ Table 1 shows the best-fit dual-mode parameters for the thermally annealed PIM6FDA-OH material and some other glassy polymers for $\mathrm{H}_{2} \mathrm{~S}, \mathrm{CO}_{2}$ and $\mathrm{CH}_{4}$ sorption.

As shown in Table 1, the Henry's law sorption coefficients of $\mathrm{H}_{2} \mathrm{~S}$ and $\mathrm{CO}_{2}, k_{\mathrm{D}}$, for the thermally annealed PIM-6FDA-OH film are significantly lower than those of 6FDA-DAM : DABA $(3: 2)$ and crosslinked TEGMC. This may be due to the higher polarity

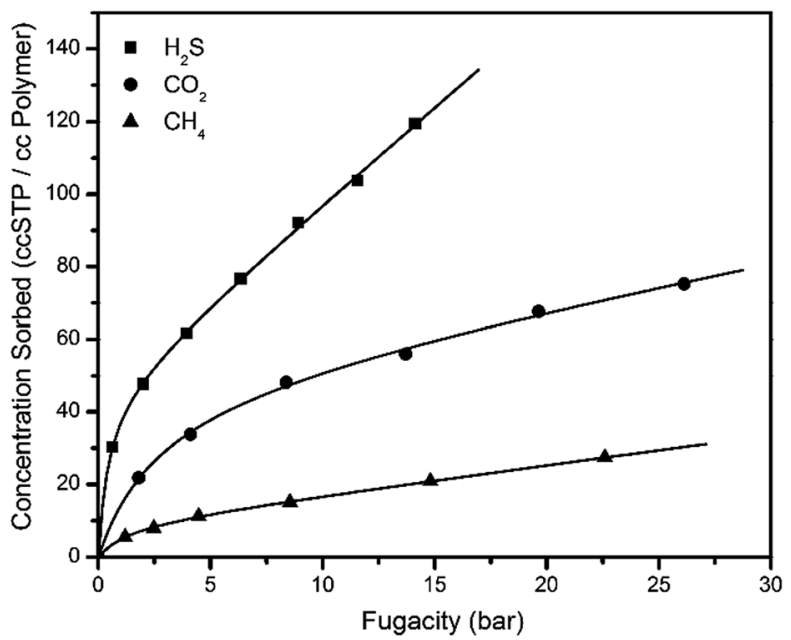

Fig. 4 Pure gas $\left(\mathrm{H}_{2} \mathrm{~S}, \mathrm{CO}_{2}\right.$, and $\left.\mathrm{CH}_{4}\right)$ sorption isotherms and dualmode model fit of thermally annealed PIM-6FDA-OH at $35^{\circ} \mathrm{C}$. 
Table 1 Dual-mode sorption model parameters for pure $\mathrm{H}_{2} \mathrm{~S}, \mathrm{CO}_{2}$ and $\mathrm{CH}_{4}{ }^{a}$

\begin{tabular}{|c|c|c|c|c|c|c|c|c|c|}
\hline Polymer & \multicolumn{3}{|l|}{$\mathrm{H}_{2} \mathrm{~S}$} & \multicolumn{3}{|l|}{$\mathrm{CO}_{2}$} & \multicolumn{3}{|l|}{$\mathrm{CH}_{4}$} \\
\hline 6FDA-DAM : DABA $(3: 2)^{b}$ & 9.55 & 38.1 & 3.81 & 2.39 & 44.0 & 0.72 & 0.06 & 27.2 & 0.19 \\
\hline TEGMC $^{c}$ & 7.16 & 38.7 & 2.87 & 2.34 & 37.0 & 0.87 & 0.27 & 27.9 & 0.13 \\
\hline
\end{tabular}

of $\mathrm{H}_{2} \mathrm{~S}$, whose sorption depends more on physiochemical interactions with the polymer than simply free volume within the matrix. However, PIM-6FDA-OH gives a significantly higher Henry's law parameter, $k_{\mathrm{D}}$, for $\mathrm{CH}_{4}$, indicating that non-polar $\mathrm{CH}_{4}$ sorption depends more on free volume within the matrix rather than physiochemical interactions with the polymer. Table 1 also shows that the total sorption capacity of the lowerdensity regions (unrelaxed gaps), characterized by the Langmuir capacity constants, $\mathrm{C}_{\mathrm{H}}^{\prime}$, of both $\mathrm{H}_{2} \mathrm{~S}$ and $\mathrm{CO}_{2}$ in the PIM-6FDA$\mathrm{OH}$ are slightly higher than those of the other polymers, which is consistent with higher fractional free volume of PIM-6FDA$\mathrm{OH}$ compared to the other materials.

To obtain insight into gas sorption levels under mixed gas feed conditions that correspond to the mixed gas permeation tests performed in this work, mixed gas sorption values were estimated using the dual-mode sorption parameters for $\mathrm{H}_{2} \mathrm{~S}$, $\mathrm{CO}_{2}$ and $\mathrm{CH}_{4}$ recorded in Table 1 according to eqn (6)-(8). Fig. 5 shows the predicted mixed gas sorption values for $\mathrm{H}_{2} \mathrm{~S}, \mathrm{CO}_{2}$ and $\mathrm{CH}_{4}$ at $35{ }^{\circ} \mathrm{C}$ with a $15 \% \mathrm{H}_{2} \mathrm{~S}, 15 \% \mathrm{CO}_{2}$, and $70 \% \mathrm{CH}_{4}$ feed mixture in the thermally annealed PIM-6FDA-OH material. Calculations were also performed with the crosslinked TEGmodified PEGMC material for comparison, and the corresponding dual-mode sorption parameters were taken from ref. 24. It can be seen that the gas sorption values for $\mathrm{H}_{2} \mathrm{~S}, \mathrm{CO}_{2}$ and $\mathrm{CH}_{4}$ are predicted to show a decrease in solubility in the mixture. Compared with the crosslinked PEGMC material, both $\mathrm{H}_{2} \mathrm{~S}$ and $\mathrm{CO}_{2}$ sorption in the thermally annealed PIM-6FDA-OH material experienced a significant reduction under mixed gas feed conditions due to lower Langmuir affinity constant values. This affinity coefficient is an equilibrium constant equal to the ratio of solute sorption and desorption rate constants from the Langmuir sites, ${ }^{32}$ associated with $\mathrm{H}_{2} \mathrm{~S}$ and $\mathrm{CO}_{2}$. However, the difference of $\mathrm{CH}_{4}$ sorption between the pure- and mixed-gas sorption isotherms in the thermally annealed PIM-6FDA-OH material was much smaller than that in the crosslinked PEGMC material due to a relatively high $\mathrm{CH}_{4}$ Langmuir affinity constant value in the PIM-6FDA-OH. This is currently not well understood, but based on the mixed gas sorption predictions, it is very clear that strong competitive sorption effects should exist in these sour gas separation systems. Although the mixed gas sorption calculations in this work are a good starting point, further research on mixed gas sorption experiments corresponding to mixed gas permeation tests would be a more useful approach for evaluating membrane performance for realistic sour gas separations. This approach may provide direct insight into how the material structure relates to competitive sorption under practically relevant operating conditions. Unfortunately, these tests were beyond the scope of the current work and we are not currently able to make direct mixed gas sorption measurements.

The pure $\mathrm{H}_{2} \mathrm{~S}, \mathrm{CO}_{2}$, and $\mathrm{CH}_{4}$ permeation isotherms for the PIM-6FDA-OH dense films at $35^{\circ} \mathrm{C}$ are shown in Fig. 6-8. It can be seen that no $\mathrm{H}_{2} \mathrm{~S}$-induced plasticization of the PIM-6FDA-OH film occurs in a pure $\mathrm{H}_{2} \mathrm{~S}$ feed at $35{ }^{\circ} \mathrm{C}$ up to 4.5 bar feed pressure, and only a slight plasticization is observed above 4.5 bar of pure $\mathrm{H}_{2} \mathrm{~S}$. This can be explained by accelerated chain relaxation and reduced free volume in the annealed samples. In our previous studies on the annealing effect on the 6FDADAM : DABA (3:2) polymer, the results showed that the annealed films exhibit non-negligible plasticization pressures. ${ }^{22}$ Increasing the annealing temperature from $180{ }^{\circ} \mathrm{C}$ to $230{ }^{\circ} \mathrm{C}$ caused an increase in the $\mathrm{H}_{2} \mathrm{~S}$ plasticization pressure of approximately $25 \%$ to a value of 2.5 bar.

Similarly, the hydroxyl-functionalized PIM films indicated significant improvement in $\mathrm{CO}_{2}$ plasticization resistance up to 28 bar feed pressure (Fig. 7). Carbon dioxide showed a higher resistance to swelling due to its lower sorption, caused by its lower critical temperature compared to $\mathrm{H}_{2} \mathrm{~S}$. In comparison, for the unannealed PIM-6FDA-OH films, $\mathrm{CO}_{2}$-induced plasticization occurred at $\sim 6.9$ bar. ${ }^{35}$ In addition to the increased plasticization resistance in the annealed films, the $\mathrm{CO}_{2}$ permeability of annealed PIM-6FDA-OH films decreased. Presumably, this is again due to accelerated chain relaxation and lower free volume effects caused by sub- $T_{\mathrm{g}}$ annealing. ${ }^{22}$ Swelling-induced plasticization is a common phenomenon for polymer membranes in gas separations involving aggressive feed streams, such as $\mathrm{CO}_{2}$ and $\mathrm{H}_{2} \mathrm{~S}$ in sour gas. ${ }^{4}$ Plasticization occurs when a penetrant significantly increases the mobility of polymer chain segments, thereby increasing the diffusion coefficients of all penetrants in the membrane. Penetrant molecules with higher critical temperatures like $\mathrm{H}_{2} \mathrm{~S}$ and $\mathrm{CO}_{2}$ are more capable of inducing swelling, because they have a considerably higher sorption capacity, particularly in glassy polymers., ${ }^{\mathbf{4 , 2 2 2 , 2 4}}$ As shown in Fig. 8, methane does not plasticize at any of the pressures investigated.

As discussed in the theory section, the permeability coefficient is defined as the product of the diffusion coefficient and the sorption coefficient; therefore, the selectivity can be decoupled into diffusion and sorption selectivity. To better understand the role of hydroxyl groups in $\mathrm{H}_{2} \mathrm{~S} / \mathrm{CH}_{4}$ and $\mathrm{CO}_{2}$ / $\mathrm{CH}_{4}$ selectivity, diffusion coefficients $(D)$ and solubility coefficients $(S)$ were measured using both the time-lag permeation 

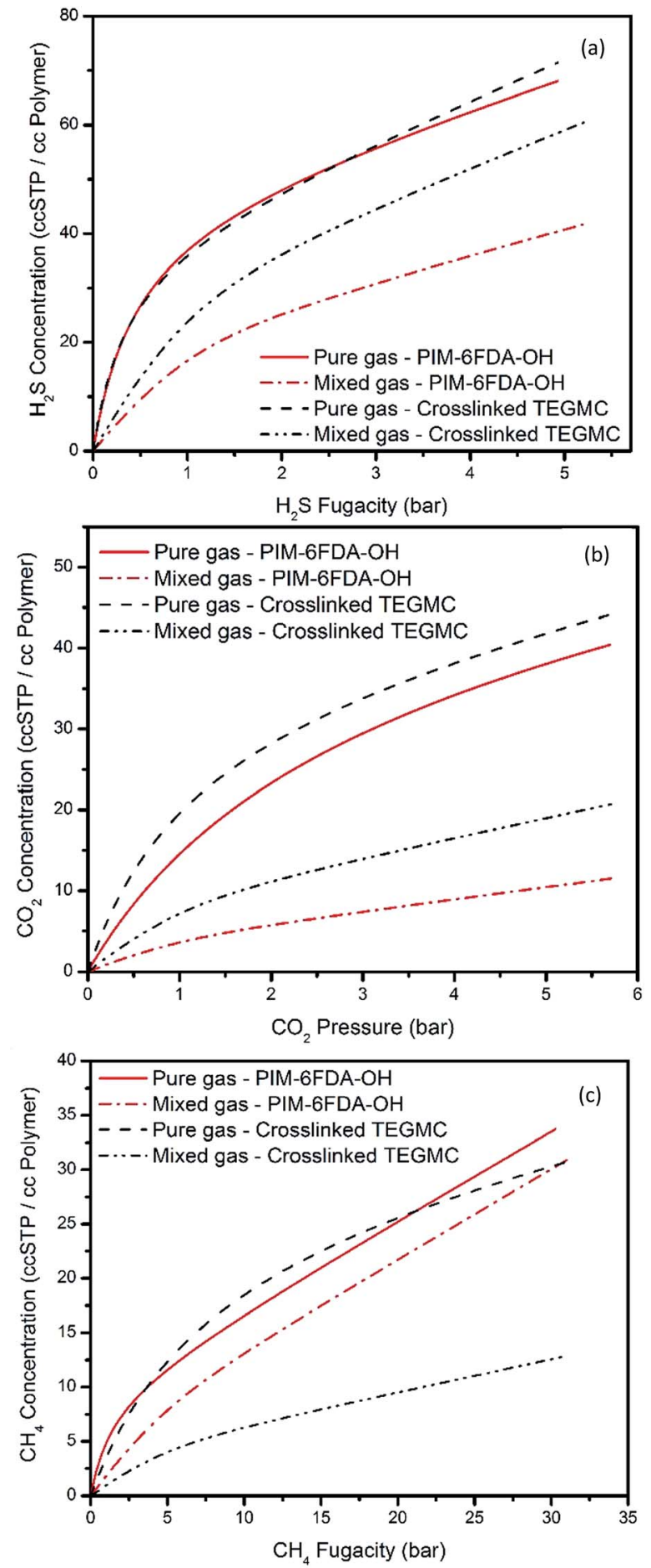

Fig. 5 Sorption isotherms at $35^{\circ} \mathrm{C}$ for the thermally annealed PIM6FDA-OH and cross-linked PEGMC films with TEG as the cross-linking agent. Pure gas dual-mode sorption model fits are plotted along with mixed gas sorption predictions for a $15 \% \mathrm{H}_{2} \mathrm{~S}, 15 \% \mathrm{CO}_{2}$, and $70 \% \mathrm{CH}_{4}$ feed mixture. The dual-mode sorption model best fit parameters of cross-linked PEGMC are adapted from ref. 24 and used for calculations.

method and pressure-decay sorption method (Fig. 4). Using the permeation and sorption results, the kinetic (diffusion) and thermodynamic (sorption) individual contributions of the

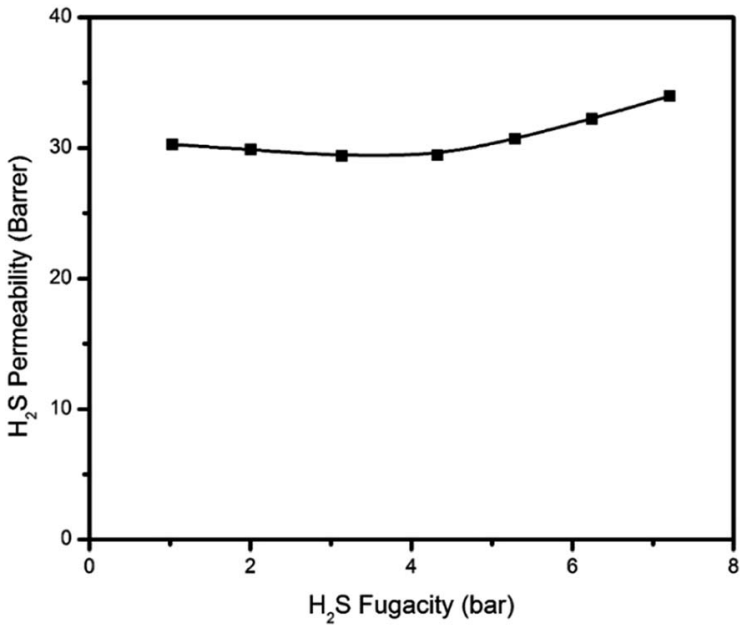

Fig. 6 Pure $\mathrm{H}_{2} \mathrm{~S}$ permeability isotherm for an annealed PIM-6FDA-OH film at $35^{\circ} \mathrm{C}$.

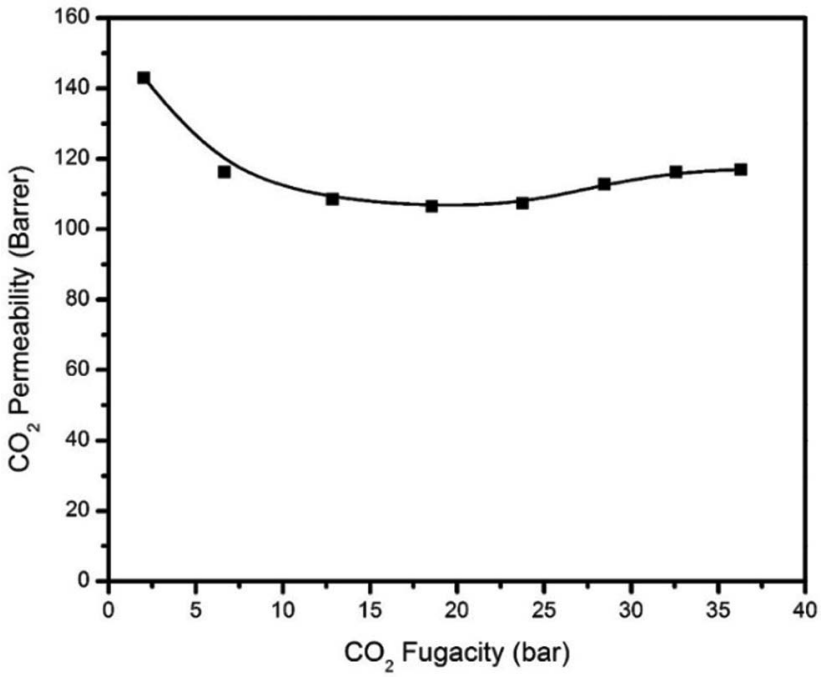

Fig. 7 Pure $\mathrm{CO}_{2}$ permeability isotherm for an annealed PIM-6FDA-OH film at $35^{\circ} \mathrm{C}$.

thermally annealed PIM-6FDA-OH and the comparison to other polymers were calculated and are shown in Table 2. It can be seen that the $D$ and $S$ values determined from the two methods are in good agreement. Despite the lower diffusion coefficients of functionalized PIM-6FDA-OH, it shows much higher $\mathrm{CO}_{2} /$ $\mathrm{CH}_{4}$ diffusion selectivity in comparison with PIM-1 and PIM-PI3 , which is more typical for a glassy polymer, with diffusion selectivity as the major contributor to overall permselectivity. ${ }^{22}$ Benefitting from the PIM segments in the molecular structure, the $\mathrm{OH}$-functionalized polymers reported in this study showed increased $\mathrm{CO}_{2} / \mathrm{CH}_{4}$ selectivity while maintaining high permeability in comparison with traditional PIMs and PIM-PIs. It can also be seen from Table 2, the $\mathrm{H}_{2} \mathrm{~S} / \mathrm{CH}_{4}$ selectivity of the thermally annealed PIM-6FDA-OH is primarily derived from the solubility contribution despite the fact that it is a glassy material. Because $\mathrm{H}_{2} \mathrm{~S}$ has a smaller kinetic diameter than $\mathrm{CH}_{4}$ and 


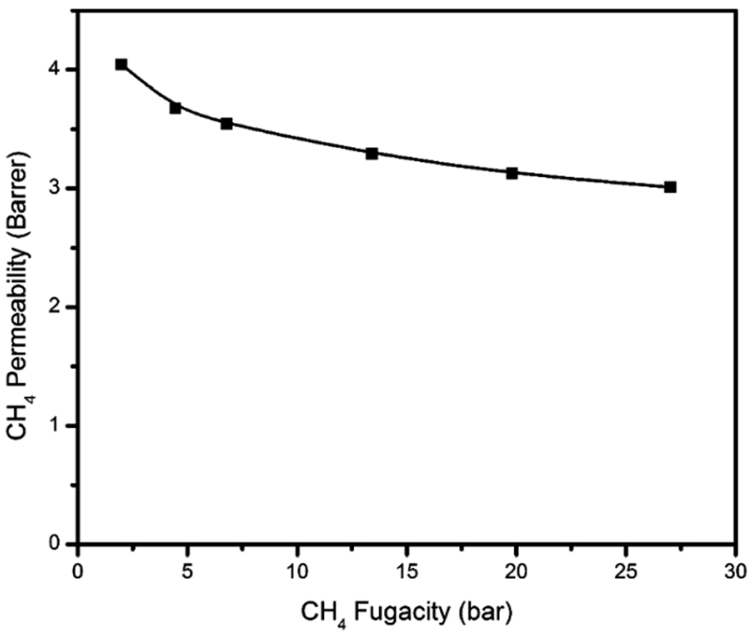

Fig. 8 Pure $\mathrm{CH}_{4}$ permeability isotherm of an annealed PIM-6FDA-OH film at $35^{\circ} \mathrm{C}$.

should be diffusion-favored, this result suggests that strong polymer- $\mathrm{H}_{2} \mathrm{~S}$ interactions decrease the diffusion coefficient of $\mathrm{H}_{2} \mathrm{~S}$ in the membrane. Similar results were observed in our previous research on 6F-PAI and 6FDA-DAM-DABA $(3: 2)$ materials. $^{21,22}$

\section{Mixed gas permeation}

Although the thermally annealed PIM-6FDA-OH film showed very promising results in pure gas feeds (Fig. 2 and 3), multicomponent mixture tests are more practical to assess its true performance. In this study, ternary gas permeation measurements were made with a $15 \% \mathrm{H}_{2} \mathrm{~S}, 15 \% \mathrm{CO}_{2}$ and $70 \% \mathrm{CH}_{4}$ mixture at upstream pressures ranging from 7 to 48 bar and with vacuum downstream. Fig. $9(\mathrm{a}-\mathrm{c})$ show the $\mathrm{H}_{2} \mathrm{~S}, \mathrm{CO}_{2}$, and $\mathrm{CH}_{4}$ permeabilities of thermally annealed PIM-6FDA-OH films in the ternary mixture, while Fig. 10(a) and (b) show the $\mathrm{H}_{2} \mathrm{~S}$ / $\mathrm{CH}_{4}$ and the $\mathrm{CO}_{2} / \mathrm{CH}_{4}$ selectivities, respectively.

As shown in Fig. 9, it is very clear from the $\mathrm{CH}_{4}$ and $\mathrm{CO}_{2}$ permeability isotherms for PIM-6FDA-OH films that plasticization did not occur even at high acid gas partial pressures. However, severe $\mathrm{H}_{2} \mathrm{~S}$-induced plasticization effects were evident at the highest feed pressure of 48 bar. This is expected due to the very high condensability of $\mathrm{H}_{2} \mathrm{~S}$ and its capacity to form polymer-penetrant interactions with the polymer backbone. It is somewhat surprising that despite the plasticization apparent for $\mathrm{H}_{2} \mathrm{~S}, \mathrm{CO}_{2}$ and $\mathrm{CH}_{4}$ as co-penetrants do not show apparent increases in permeabilities for the same mixed gas feed. Similar results were observed in our previous studies using 6FDA-DAM-DABA (3:2) and CA materials., ${ }^{\mathbf{4 , 2 2 , 2 4}}$ Again, as shown in Fig. 6, in pure gas feed, $\mathrm{H}_{2} \mathrm{~S}$-induced plasticization of the thermally annealed PIM-6FDA-OH film did not occur until the $\mathrm{H}_{2} \mathrm{~S}$ feed pressure was higher than 4.5 bar (only a slight change even at 8 bar), which means the annealed PIM-6FDA-OH film has a much less pronounced plasticization response. Clearly, the plasticization/swelling effects under aggressive conditions that caused a reduction of $\mathrm{CO}_{2} / \mathrm{CH}_{4}$ selectivity to about 15 (unpublished data) in nonannealed films were significantly minimized in the films annealed at $250{ }^{\circ} \mathrm{C}$. Interestingly, Fig. 10 shows that when the $\mathrm{CO}_{2} / \mathrm{CH}_{4}$ selectivity decreases, the $\mathrm{H}_{2} \mathrm{~S} / \mathrm{CH}_{4}$ selectivity increases with increasing feed pressure. This is because in a ternary system, the highly condensable gases, $\mathrm{CO}_{2}$ and $\mathrm{H}_{2} \mathrm{~S}$, now have to compete for the Langmuir sorption sites. ${ }^{4}$ Because $\mathrm{H}_{2} \mathrm{~S}$ has a higher affinity for these sorption sites, the sorption capacity of $\mathrm{CO}_{2}$ is presumably greatly reduced. This leads to a decrease of $\mathrm{CO}_{2}$ permeability whereas an increase of $\mathrm{H}_{2} \mathrm{~S}$ permeability is observed. Methane is not greatly affected in this case because it already has lower affinity for the Langmuir sorption sites than both $\mathrm{CO}_{2}$ and $\mathrm{H}_{2} \mathrm{~S}$, which shows a similar trend to cellulose acetate and thermally annealed 6FDA-DAMDABA (3:2) films., ${ }^{4,22}$ It should be noted that at the high end of the pressure range (48 bar), the $\mathrm{H}_{2} \mathrm{~S} / \mathrm{CH}_{4}$ selectivity reached nearly 30 in the thermally annealed PIM-6FDA-OH film, which is much higher than most other glassy polymers $(\sim 15)$ and is very competitive compared with rubbery polymers. More interestingly, the $\mathrm{CO}_{2} / \mathrm{CH}_{4}$ selectivity ( 25) suffers less significant loss versus the non-annealed sample, indicating the thermally annealed $\mathrm{OH}$-functionalized spiro-polyimides in

Table 2 Diffusion coefficient $(D)$, solubility coefficient $(S)$, diffusion selectivity $\left(\alpha_{\mathrm{D}}\right)$, and solubility selectivity $\left(\alpha_{\mathrm{S}}\right)$ of PIMs-6FDA-OH and other polymers at $35^{\circ} \mathrm{C}$

\begin{tabular}{|c|c|c|c|c|c|c|c|c|c|c|}
\hline \multirow[b]{2}{*}{ Polymer } & \multicolumn{3}{|c|}{$D\left(10^{-8} \mathrm{~cm}^{2} \mathrm{~s}^{-1}\right)$} & \multicolumn{3}{|c|}{$\begin{array}{l}S\left(10^{-2} \mathrm{~cm}^{3}(\mathrm{STP}) \mathrm{cm}^{-3}\right. \\
\left.\mathrm{cmHg}^{-1}\right)\end{array}$} & \multicolumn{2}{|l|}{$\alpha_{\mathrm{D}}$} & \multicolumn{2}{|l|}{$\alpha_{\mathrm{S}}$} \\
\hline & $\mathrm{CH}_{4}$ & $\mathrm{CO}_{2}$ & $\mathrm{H}_{2} \mathrm{~S}$ & $\mathrm{CH}_{4}$ & $\mathrm{CO}_{2}$ & $\mathrm{H}_{2} \mathrm{~S}$ & $\mathrm{CO}_{2} / \mathrm{CH}_{4}$ & $\mathrm{H}_{2} \mathrm{~S} / \mathrm{CH}_{4}$ & $\mathrm{CO}_{2} / \mathrm{CH}_{4}$ & $\mathrm{H}_{2} \mathrm{~S} / \mathrm{CH}_{4}$ \\
\hline PIMs-6FDA-OH ${ }^{a}$ & 0.844 & 8.92 & 0.637 & 4.98 & 16.7 & 46.4 & 10.6 & 0.75 & 3.35 & 9.3 \\
\hline PIMs-6FDA-OH ${ }^{b}$ & 0.868 & 9.61 & 0.599 & 4.84 & 15.5 & 49.3 & 11.1 & 0.69 & 3.20 & 10.2 \\
\hline PIMs-6FDA-OH $^{c}$ & 2.02 & 9.88 & - & 4.51 & 26.7 & - & 4.89 & - & 5.92 & - \\
\hline $\mathrm{PIM}_{-1}^{d}$ & 6.8 & 26 & - & 18 & 88 & - & 3.82 & - & 4.89 & - \\
\hline PIM-PI- $3^{e}$ & 3 & 12 & - & 9.3 & 44 & - & 4.0 & - & 4.73 & - \\
\hline $\mathrm{CA}^{f}$ & 0.21 & 0.86 & 0.34 & 0.62 & 4.93 & 14.0 & 4.09 & 1.63 & 7.99 & 22.7 \\
\hline Crosslinked PDMC ${ }^{g}$ & 0.82 & 7.18 & 1.07 & 2.79 & 12.2 & 20.9 & 8.70 & 1.29 & 4.37 & 7.49 \\
\hline
\end{tabular}

${ }^{a} D$ is determined by the constant volume time-lag method; $S$ is deduced based on the equation $P=D S .{ }^{b} S$ is measured by pressure-decay sorption; $D$ is calculated from $P=D S .{ }^{c}$ Data from ref. $35 .{ }^{d}$ Data from ref. $44 .{ }^{e}$ Data from ref. $45 .{ }^{f}$ Data from ref. $4 .{ }^{g}$ Data from ref. 38. 

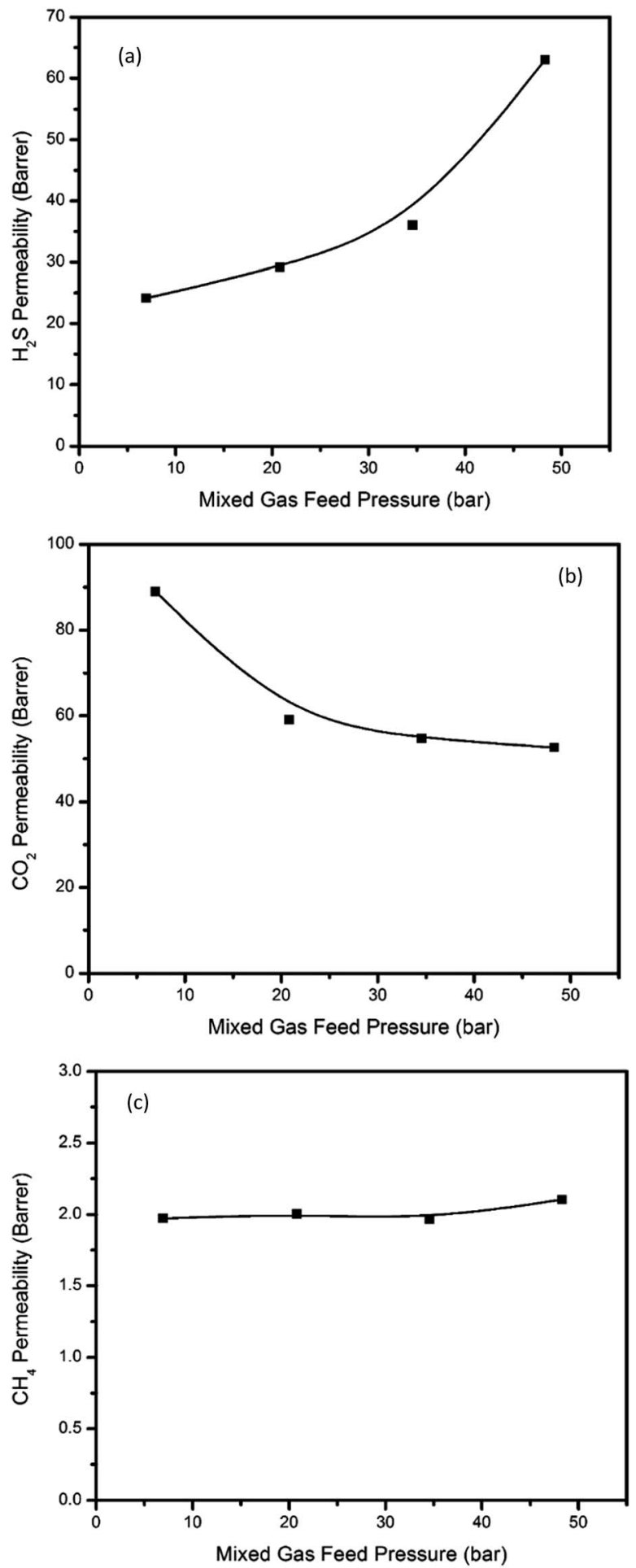

Fig. 9 Mixed gas $\left(15 \% \mathrm{H}_{2} \mathrm{~S}, 15 \% \mathrm{CO}_{2}, 70 \% \mathrm{CH}_{4}\right)$ permeabilities in PIM6FDA-OH films at $35^{\circ} \mathrm{C}$.

this study plasticized significantly less as compared to conventional non-crosslinked 6FDA-based polyimides. This unique performance at high pressures is very impressive, since most literature reports on rubbery polymers, which generally show very high $\mathrm{H}_{2} \mathrm{~S} / \mathrm{CH}_{4}$ selectivity, were determined only at low $\mathrm{H}_{2} \mathrm{~S}$ concentrations and low pressures.
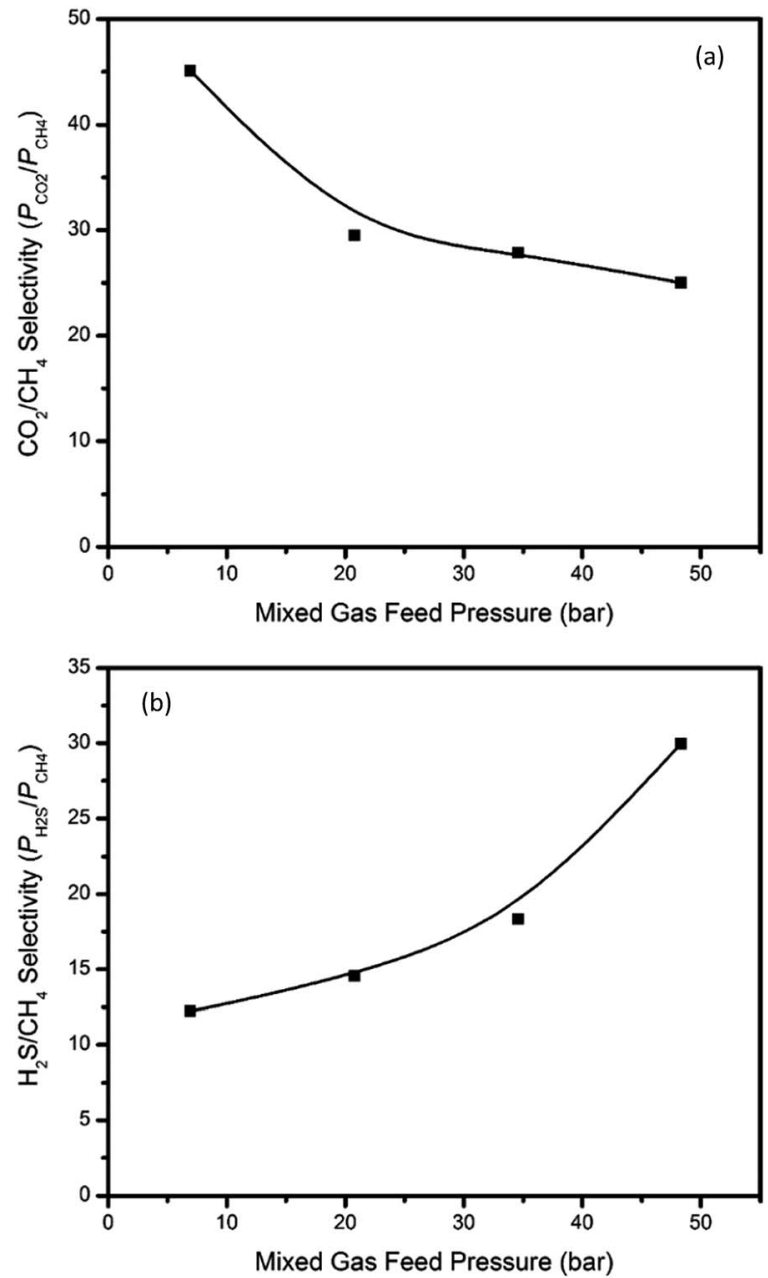

Fig. 10 Mixed gas $\left(15 \% \mathrm{H}_{2} \mathrm{~S}, 15 \% \mathrm{CO}_{2}, 70 \% \mathrm{CH}_{4}\right)$ selectivities for acid gases of PIM-6FDA-OH at $35^{\circ} \mathrm{C}$.

\section{Pure and mixed gas permeation modeling}

The partial immobilization model (dual-mode extension) and dual-mode sorption parameters for each gas can be used in the predictions of pure gas permeation values in the absence of plasticization or swelling or swelling induced bulk flow effects. ${ }^{34}$ The above coefficients are deceptively simple in appearance; however, depending on the assumptions made, their interpretation can be complex. To enable readers to understand these issues, we have provided details in the ESI, $\dagger$ while presenting the key results of these detailed analysis in summary form here. Fig. 11 shows the experimental permeability data as well as the partial immobilization model predictions for pure $\mathrm{H}_{2} \mathrm{~S}, \mathrm{CO}_{2}$, and $\mathrm{CH}_{4}$ permeability through the thermally annealed PIM6FDA-OH film. These curves indicate good agreement between the measured permeation data and the model predictions prior to the point at which $\mathrm{H}_{2} \mathrm{~S}$ - and $\mathrm{CO}_{2}$-induced plasticization occurs and within the entire $\mathrm{CH}_{4}$ permeability isotherm.

Permeation modeling based on dual-mode transport through glassy polymers can also be extended to mixed gases (eqn S5 in the ESI $\dagger$ ). ${ }^{34}$ Because the dual-mode model parameters are calculated based on pure gas permeation and sorption data, 


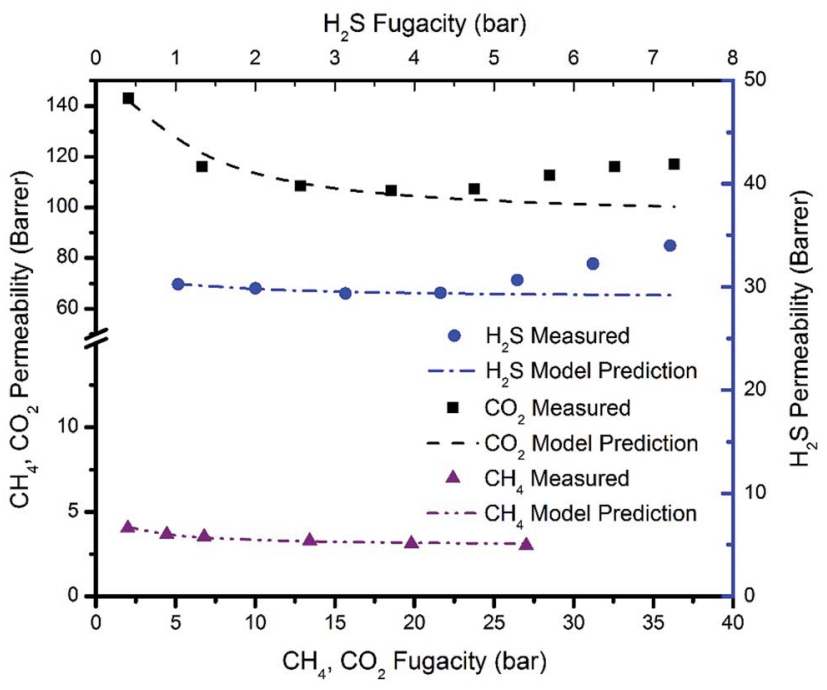

Fig. 11 Partial immobilization model projections for pure $\mathrm{H}_{2} \mathrm{~S}, \mathrm{CO}_{2}$ and $\mathrm{CH}_{4}$ permeability at $35{ }^{\circ} \mathrm{C}$ in the thermally annealed PIM-6FDA$\mathrm{OH}$ films.

deviations between mixed gas experimental permeation data and model predictions can be observed in some cases, especially for mixed gas feeds that lead to significant polymerpenetrant interactions or other effects that are not accounted for in the model. More complex models should be used in these cases. For instance, the so called "frame of reference" (or bulk flow) model can be used to account for bulk (convective) flux through the membrane (eqn S12-S22 in the ESI $\dagger$ ). The bulk flux contribution usually becomes non-negligible under mixed gas feed conditions, especially when highly condensable species (like $\mathrm{CO}_{2}$ and $\mathrm{H}_{2} \mathrm{~S}$ ) are present. The detailed interpretation of these models and difference for the various penetrants are provided in the ESI. $\dagger$

The dual-mode and frame of reference models were applied for permeation predictions for a $15 \% \mathrm{H}_{2} \mathrm{~S}, 15 \% \mathrm{CO}_{2}$, and $70 \%$ $\mathrm{CH}_{4}$ mixed gas feed with the thermally annealed PIM-6FDA-OH films. The results are shown in Fig. 12 and 13. The predicted permeability and permselectivity values given by both models (especially the more complicated frame of reference model with bulk flux contributions) are in close agreement with the experimental values for some cases for binary mixtures in the literature, ${ }^{34,47-49}$ For the current case, however, it is clear from the permeability and permselectivity calculations shown in Fig. 12 and 13 that the presence of $\mathrm{H}_{2} \mathrm{~S}$ in the feed mixture adds unexpected complexity to the system. The permeability and permselectivity values given by both models are quite poor in capturing the experimentally observed trends, even when the frame of reference is accounted for in the bulk flow model. The experimental permeability values for $\mathrm{CO}_{2}$ and $\mathrm{CH}_{4}$ are far below the model predictions, whereas $\mathrm{H}_{2} \mathrm{~S}$ experimental values are well above the model predictions at higher feed pressures. Additionally, the predicted $\mathrm{H}_{2} \mathrm{~S} / \mathrm{CH}_{4}$ permselectivities are far below the measured values, while the measured $\mathrm{CO}_{2} / \mathrm{CH}_{4}$ permselectivities are well above the predicted value at lower feed pressure, although the frame of reference model can
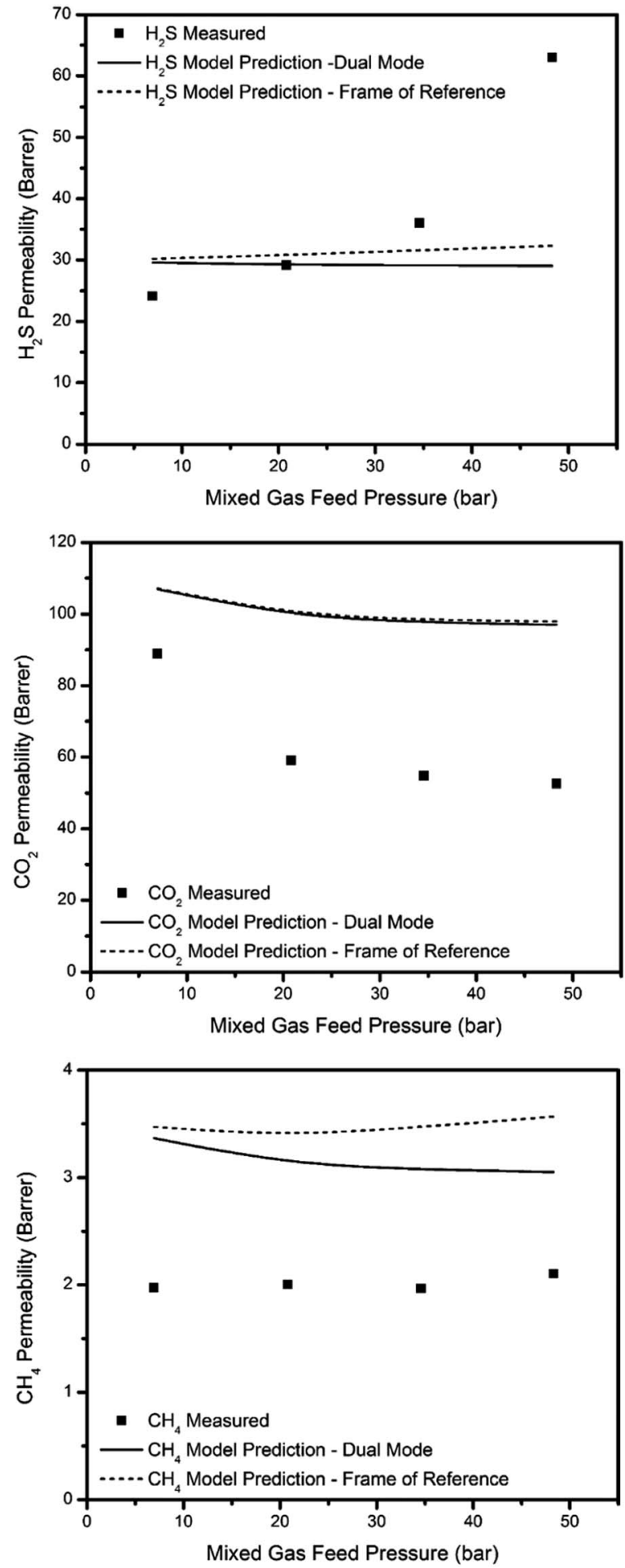

Fig. 12 Model predictions for $\mathrm{H}_{2} \mathrm{~S}, \mathrm{CO}_{2}$, and $\mathrm{CH}_{4}$ permeability of a $15 \%$ $\mathrm{H}_{2} \mathrm{~S}, 15 \% \mathrm{CO}_{2}$, and $70 \% \mathrm{CH}_{4}$ mixed gas feed with thermally annealed PIM-6FDA-OH films.

describe the $\mathrm{CO}_{2} / \mathrm{CH}_{4}$ permselectivities fairly well at the higher feed pressures. It is interesting to note that the frame of reference model gives significantly different predictions for permeability of $\mathrm{H}_{2} \mathrm{~S}$ and $\mathrm{CH}_{4}$, and $\mathrm{CO}_{2} / \mathrm{CH}_{4}$ permselectivity than the simpler dual-mode model, however, the predictions in both 

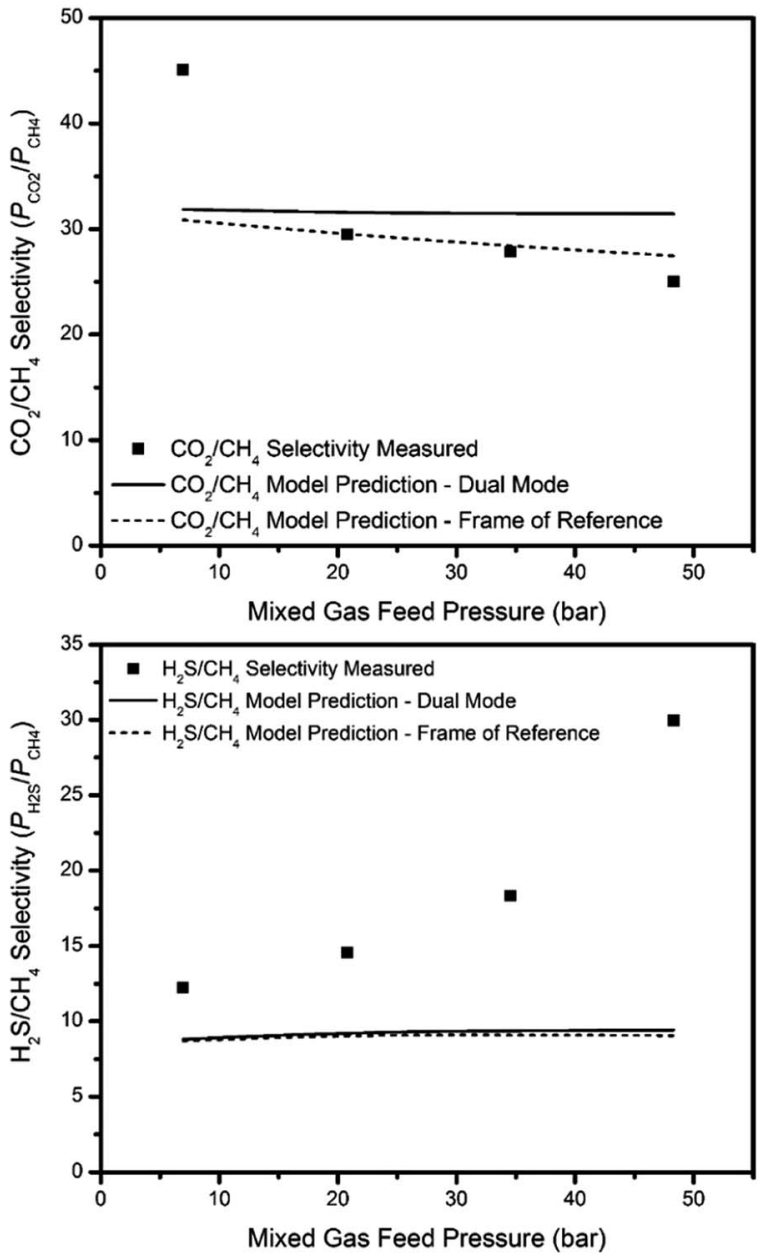

Fig. $13 \mathrm{H}_{2} \mathrm{~S} / \mathrm{CH}_{4}$ and $\mathrm{CO}_{2} / \mathrm{CH}_{4}$ permselectivity projections for $15 \%$ $\mathrm{H}_{2} \mathrm{~S}, 15 \% \mathrm{CO}_{2}$, and $70 \% \mathrm{CH}_{4}$ mixed gas feed at $35^{\circ} \mathrm{C}$. cases are rather poor. Although at this time it is not possible to identify the exact transport mechanism leading to the poor agreement between observed permeation results and model projections in ternary mixtures containing $\mathrm{H}_{2} \mathrm{~S}$, it clearly deserves further investigation. Future work in this area will include considerations of models that may address the two models considered here for sour gas permeation performance of the glassy polymers used in this work.

Table 3 summarizes most of the mixed gas studies that have been conducted on polymeric dense films for sour gas separations. It is clear that the performance of the thermally annealed PIM-6FDA-OH films is very impressive compared to most other polymers shown in this table. The $\mathrm{H}_{2} \mathrm{~S} / \mathrm{CH}_{4}$ selectivity is 30 at 48 bar, which is much higher than most other glassy polymers, and $\mathrm{H}_{2} \mathrm{~S}$ permeability is also much higher than cellulose acetate, 6FDA-DAM : DABA $(3: 2)$ and novel 6FDA-PAI materials. ${ }^{21}$ Even compared with rubbery polymers, PIM-6FDA-OH still shows competitive $\mathrm{H}_{2} \mathrm{~S} / \mathrm{CH}_{4}$ selectivity and much higher $\mathrm{CO}_{2} / \mathrm{CH}_{4}$ selectivity, which indicates that this unique $\mathrm{OH}$-functionalized PIM-PI membrane can be a very promising candidate for aggressive sour gas separations. Although PIM-6FDA-OH performance is similar to that of the crosslinked TEGMC and DEGMC, the avoidance of the need to crosslink the PIM-6FDA$\mathrm{OH}$ may be a practical advantage.

Based on the mixed gas permeation results, the performance of thermally annealed PIM-6FDA-OH films for aggressive sour gas separations appears quite promising. However, due to the inherent differences between rubbery and glassy polymers in terms of $\mathrm{CO}_{2} / \mathrm{CH}_{4}$ and $\mathrm{H}_{2} \mathrm{~S} / \mathrm{CH}_{4}$ separations, it is difficult to compare the efficiency of these two different material types for the overall sour gas separation. Therefore, it is helpful to use a separation efficiency term referred to as "combined acid gas selectivity $\left(\alpha_{\mathrm{CAG}}\right)$ " that takes both of the separations into account, giving a measure of overall performance of different

Table 3 Comparison of PIM-6FDA-OH with other polymers in ternary mixed gas feeds at $35^{\circ} \mathrm{C}$

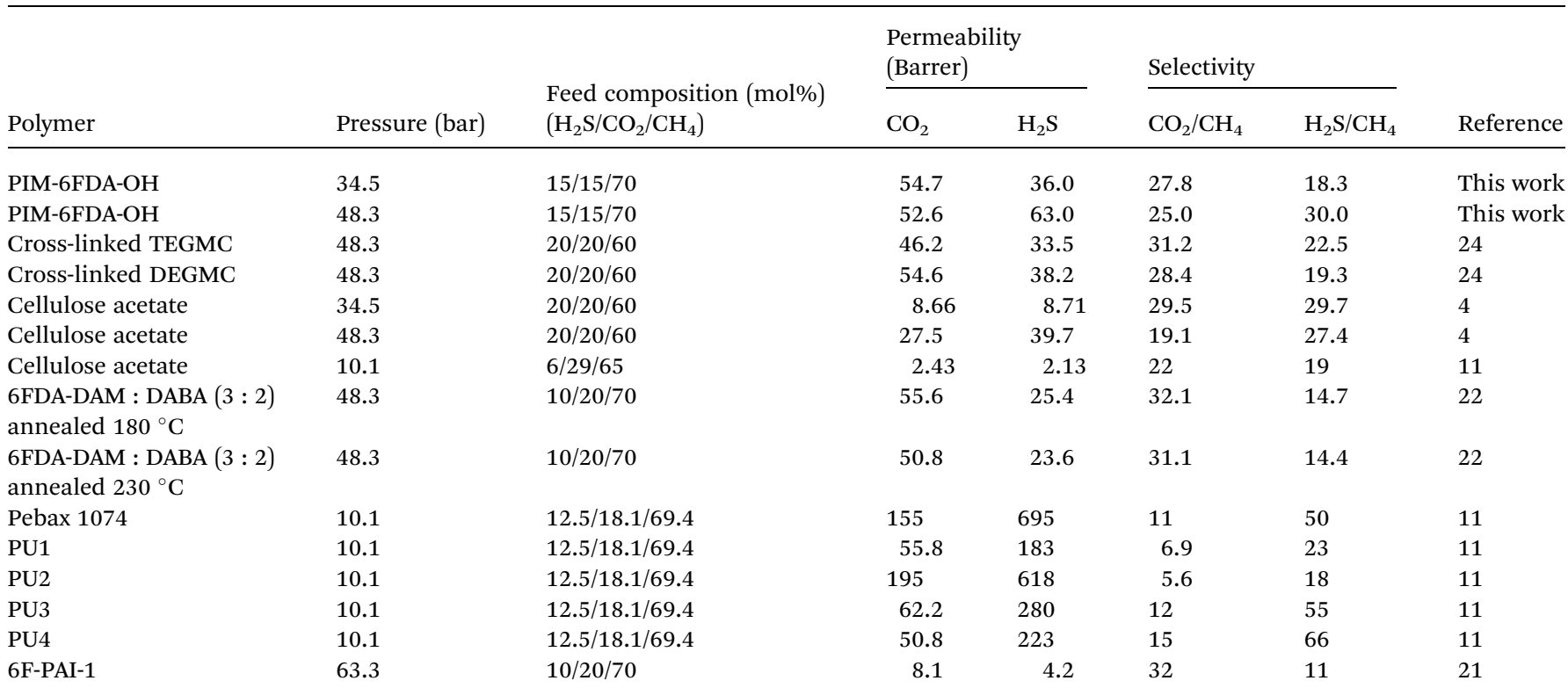




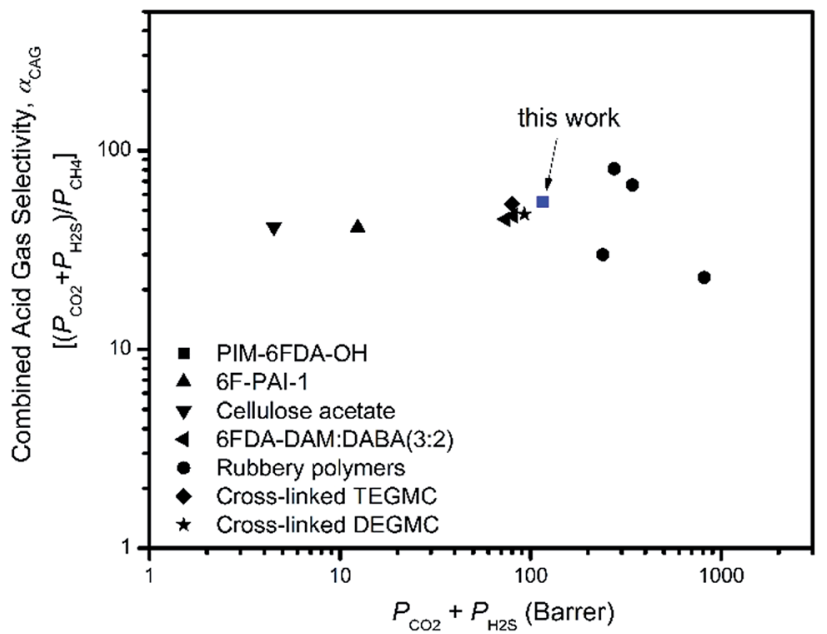

Fig. 14 Productivity-efficiency trade-off for combined acid gas separations. Ternary gas data are shown for rubbers (black symbols) as well as PIM-6FDA-OH and some other glassy polymers, 6F-PAI-1, CA and 6FDA-DAM : DABA (3:2). The data points for PIM-6FDA-OH, 6FPAI-1, and 6FDA-DAM : DABA (3:2) correspond to ternary sour gas mixtures with a total feed pressure greater than 34.5 bar $\left(15 \% \mathrm{H}_{2} \mathrm{~S}, 15 \%\right.$ $\mathrm{CO}_{2}, 70 \% \mathrm{CH}_{4}$ for PIM-6FDA-OH; $10 \% \mathrm{H}_{2} \mathrm{~S}, 20 \% \mathrm{CO}_{2}, 70 \% \mathrm{CH}_{4}$ for $6 \mathrm{~F}-$ PAI-1 and 6FDA-DAM : DABA (3:2)); CA data were tested under 10.1 bar with ternary sour gas mixtures $6 \% \mathrm{H}_{2} \mathrm{~S}, 29 \% \mathrm{CO}_{2}$, and $65 \% \mathrm{CH}_{4}$; rubbery polymers were tested under 10.1 bar with ternary sour gas mixtures $12 \% \mathrm{H}_{2} \mathrm{~S}, 18 \% \mathrm{CO}_{2}$, and $70 \% \mathrm{CH}_{4}$; the data for $6 \mathrm{~F}-\mathrm{PAl}-1$ are adapted from ref. 21; the data for 6FDA-DAM:DABA (3:2) are adapted from ref. 22; the data for $C A$ and the rubbery polymers are adapted from ref. 11. The data for crosslinked PEGMC are adapted from ref. 24.

polymer materials. The so-called "combined acid gas selectivity $\left(\alpha_{\mathrm{CAG}}\right)$ " is defined as the ratio of combined acid gas permeability $\left(P_{\mathrm{H}_{2} \mathrm{~S}}+P_{\mathrm{CO}_{2}}\right)$ and methane permeability $\left(P_{\mathrm{CH}_{4}}\right)$. Using this parameter, the results of this work are compared to the literature data in Table 3 through a combined acid gas productivity $\left(P_{\mathrm{H}_{2} \mathrm{~S}}+P_{\mathrm{CO}_{2}}\right)$-efficiency $\left(\alpha_{\mathrm{CAG}}\right)$ trade-off plot (Fig. 14). It can be seen that the location of PIM-6FDA-OH near the upper right quadrant indicates that this material performs significantly better than CA and 6F-PAI based on the combined acid gas metric. It also appears to be very competitive with the majority of the rubbery polymers. Moreover, the sour gas testing conditions considered here are more aggressive than those examined with these rubbery materials. An additional factor to mention is the ultimate form which practical membranes will take for acid gas treatment. Specifically, asymmetric hollow fibers with very high surface to volume packing efficiency are desired. Both the glassy 6FDA-DAM-DABA and PIM-6FDA-OH have the practical ability to be formed into ultrathin selective layers $(\leq 0.1 \mu \mathrm{m})$. On the other hand, forming defect-free rubbery selective layers less than one micron is very challenging. Furthermore, the $P / l=n_{c} l$ $\Delta f_{c i}$, the true measure of productivity of the two glassy polymers may exceed that of corresponding rubbery materials such as those shown in Fig. 14. Formation of such high performance asymmetric glassy polymer membranes based on either 6FDADAM-DABA or PIM-6FDA-OH is beyond the scope of the current work. Nevertheless, addressing the relative ease of forming such membranes will be important objectives in our work. Alternative PIM materials are currently explored in our groups to further improve the performance for aggressive sour gas separations..$^{50-53}$

\section{Conclusions}

A hydroxyl-functionalized polymer with intrinsic microporosity (PIM-6FDA-OH) was successfully synthesized using $3,3,3^{\prime}, 3^{\prime}$ tetramethyl-1,1'-spirobisindane-5,5'-diamino-6,6'-diol with 6FDA. Aggressive sour gas separations using thermally annealed PIM-6FDA-OH films with pure and mixed gases were investigated through permeation and sorption testing. Pure gas permeation tests on the thermally annealed PIM-6FDA-OH films showed that this novel polymer is more permeable than most traditional polyimides owing to the intrinsic microporosity introduced by the OH-containing PIM segments. $\mathrm{H}_{2} \mathrm{~S}$ induced plasticization did not occur until approximately 4.5 bar feed pressure, and $\mathrm{CO}_{2}$-induced plasticization was not apparent until greater than $28 \mathrm{bar}$, indicating greatly improved $\mathrm{CO}_{2}$ and $\mathrm{H}_{2} \mathrm{~S}$ plasticization resistance compared to unannealed films and other 6FDA-based polyimide materials. Mixed gas permeation results showed that at the highest test pressures, excellent $\mathrm{CO}_{2} / \mathrm{CH}_{4}$ selectivity was still maintained, while the $\mathrm{H}_{2} \mathrm{~S} / \mathrm{CH}_{4}$ selectivity reached nearly 30 in the thermally annealed PIM6FDA-OH film. This selectivity is much better than that of most other glassy polymers and is very competitive even compared with rubbery polymers. Based on the pure and mixed gas transport results of this study, the novel PIM-6FDA-OH materials appear to provide excellent acid gas permeability, $\mathrm{CO}_{2} / \mathrm{CH}_{4}$ selectivity, $\mathrm{H}_{2} \mathrm{~S} / \mathrm{CH}_{4}$ selectivity, and much improved penetrantinduced plasticization resistance. By introducing the combined acid gas selectivity, the productivity and efficiency performance of glassy and rubbery polymer membranes for sour gas separations were compared, showing that the hydroxyl-functionalized PIM-PI polymer is potentially a very promising candidate for aggressive sour gas separations.

\section{Acknowledgements}

The authors would like to thank King Abdullah University of Science and Technology (KAUST) for generously funding this work (Award No. KUS-I1-011-21 for William Koros and KAUST CCF funding for Ingo Pinnau).

\section{Notes and references}

1 The U.S. Energy Information Administration (EIA), Annual Energy Outlook 2014, Release Date, May 7, 2014.

2 R. W. Baker and K. Lokhandwala, Ind. Eng. Chem. Res., 2008, 47, 2109-2121.

3 J. T. Vaughn, W. J. Koros, J. R. Johnson and O. Karvan, J. Membr. Sci., 2012, 401-402, 163-174.

4 C. S. K. Achoundong, N. Bhuwania, S. K. Burgess, O. Karvan, J. R. Johnson and W. J. Koros, Macromolecules, 2013, 46, 5584-5594. 
5 D. M. Amirkhanov, A. A. Kotenko, M. N. Tul'skii and M. M. Chelyak, Fibre Chem., 2001, 33, 67-72.

6 C. J. Orme and F. F. Stewart, J. Membr. Sci., 2005, 253, 243249.

7 B. D. Bhide, A. Voskericyan and S. A. Stern, J. Membr. Sci., 1998, 140, 27-49.

8 W. Qiu, C. C. Chen, L. Xu, L. Cui, D. R. Paul and W. J. Koros, Macromolecules, 2011, 44, 6046-6056.

9 Y. F. Li, Q. P. Xin, H. Wu, R. L. Guo, Z. Z. Tian, Y. Liu, S. F. Wang, G. W. He, F. S. Pan and Z. Y. Jiang, Energy Environ. Sci., 2014, 7, 1489-1499.

10 N. Y. Du, H. B. Park, M. M. Dal-Cin and M. D. Guiver, Energy Environ. Sci., 2012, 5, 7306-7322.

11 G. Chatterjee, A. A. Houde and S. A. Stern, J. Membr. Sci., 1997, 135, 99-106.

12 L. M. Robeson, J. Membr. Sci., 2008, 320, 390-400.

13 L. M. Robeson, J. Membr. Sci., 1991, 62, 165-185.

14 L. Xu, C. Zhang, M. Rungta, W. Qiu, J. Liu and W. J. Koros, J. Membr. Sci., 2014, 459, 223-232.

15 C. Ma and W. J. Koros, J. Membr. Sci., 2013, 428, 251-259.

16 Q. L. Song, S. K. Nataraj, M. V. Roussenova, J. C. Tan, D. J. Hughes, W. Li, P. Bourgoin, M. A. Alam, A. K. Cheetham, S. A. Al-Muhtaseb and E. Sivaniah, Energy Environ. Sci., 2012, 5, 8359-8369.

17 L. Cui, W. Qiu, D. R. Paul and W. J. Koros, Polymer, 2011, 52, 3374-3380.

18 I. C. Omole, S. J. Miller and W. J. Koros, Macromolecules, 2008, 41, 6367-6375.

19 J. H. Kim, W. J. Koros and D. R. Paul, Polymer, 2006, 47, 3094-3103.

20 M. R. Coleman and W. J. Koros, J. Membr. Sci., 1990, 50, 285297.

21 J. T. Vaughn and W. J. Koros, J. Membr. Sci., 2014, 465, 107116.

22 B. Kraftschik, W. J. Koros, J. R. Johnson and O. Karvan, J. Membr. Sci., 2013, 428, 608-619.

23 S. Keskin and D. S. Sholl, Energy Environ. Sci., 2010, 3, 343351.

24 B. Kraftschik and W. J. Koros, Macromolecules, 2013, 46, 6908-6921.

25 J. D. Wind, D. R. Paul and W. J. Koros, J. Membr. Sci., 2004, 228, 227-236.

26 J. D. Wind, S. M. Sirard, D. R. Paul, P. F. Green, K. P. Johnston and W. J. Koros, Macromolecules, 2003, 36, 6433-6441.

27 A. M. Kratochvil and W. J. Koros, Macromolecules, 2010, 43, 4679-4687.

28 J. R. Wiegand, Z. P. Smith, Q. Liu, C. T. Patterson, B. D. Freeman and R. L. Guo, J. Mater. Chem. A, 2014, 2, 13309-13320.
29 L. M. Robeson, Z. P. Smith, B. D. Freeman and D. R. Paul, J. Membr. Sci., 2014, 453, 71-83.

30 T. Mohammadi, M. T. Moghadam, M. Saeidi and M. Mahdyarfar, Ind. Eng. Chem. Res., 2008, 47, 7361-7367.

31 W. J. Koros, D. R. Paul and A. A. Rocha, J. Polym. Sci., Part B: Polym. Phys., 1976, 14, 687-702.

32 W. J. Koros, A. H. Chan and D. R. Paul, J. Membr. Sci., 1977, 2, 165-190.

33 W. J. Koros, J. Polym. Sci., Part B: Polym. Phys., 1980, 18, 981992.

34 W. J. Koros, R. T. Chern, V. Stannett and H. B. Hopfenberg, J. Polym. Sci., Part B: Polym. Phys., 1981, 19, 1513-1530.

35 X. Ma, R. Swaidan, Y. Belmabkhout, Y. Zhu, E. Litwiller, M. Jouiad, I. Pinnau and Y. Han, Macromolecules, 2012, 45, 3841-3849.

36 A. L. Kohl and R. Nielsen, Gas purification, Gulf Professional Publishing, 1997.

37 R. Swaidan, B. Ghanem, E. Litwiller and I. Pinnau, J. Membr. Sci., 2015, 475, 571-581.

38 C. S. K. Achoundong, PhD dissertation, Georgia Institute of Technology, 2013.

39 T. T. Moore, S. Damle, P. J. Williams and W. J. Koros, J. Membr. Sci., 2004, 245, 227-231.

40 S. Damle and W. J. Koros, Ind. Eng. Chem. Res., 2003, 42, 6389-6395.

41 K. C. O'Brien, W. J. Koros, T. A. Barbari and E. S. Sanders, J. Membr. Sci., 1986, 29, 229-238.

42 L. M. Costello and W. J. Koros, Ind. Eng. Chem. Res., 1992, 31, 2708-2714.

43 C. H. Jung and Y. M. Lee, Macromol. Res., 2008, 16, 555-560.

44 P. M. Budd, K. J. Msayib, C. E. Tattershall, B. S. Ghanem, K. J. Reynolds, N. B. McKeown and D. Fritsch, J. Membr. Sci., 2005, 251, 263-269.

45 B. S. Ghanem, N. B. McKeown, P. M. Budd, J. D. Selbie and D. Fritsch, Adv. Mater., 2008, 20, 2766-2771.

46 W. J. Koros and D. R. Paul, J. Polym. Sci., Part B: Polym. Phys., 1976, 14, 1903-1907.

47 O. Esekhile, W. L. Qiu and W. J. Koros, J. Polym. Sci., Part B: Polym. Phys., 2011, 49, 1605-1620.

48 M. Das and W. J. Koros, J. Membr. Sci., 2010, 365, 399-408.

49 H. D. Kamaruddin and W. J. Koros, J. Membr. Sci., 1997, 135, 147-159.

50 R. Swaidan, B. S. Ghanem, E. Litwiller and I. Pinnau, J. Membr. Sci., 2014, 457, 95-102.

51 R. Swaidan, M. Al-Saeedi, B. Ghanem, E. Litwiller and I. Pinnau, Macromolecules, 2014, 47, 5104-5114.

52 B. S. Ghanem, R. Swaidan, X. Ma, E. Litwiller and I. Pinnau, Adv. Mater., 2014, 26, 6696-6700.

53 B. S. Ghanem, R. Swaidan, E. Litwiller and I. Pinnau, Adv. Mater., 2014, 26, 3688-3692. 